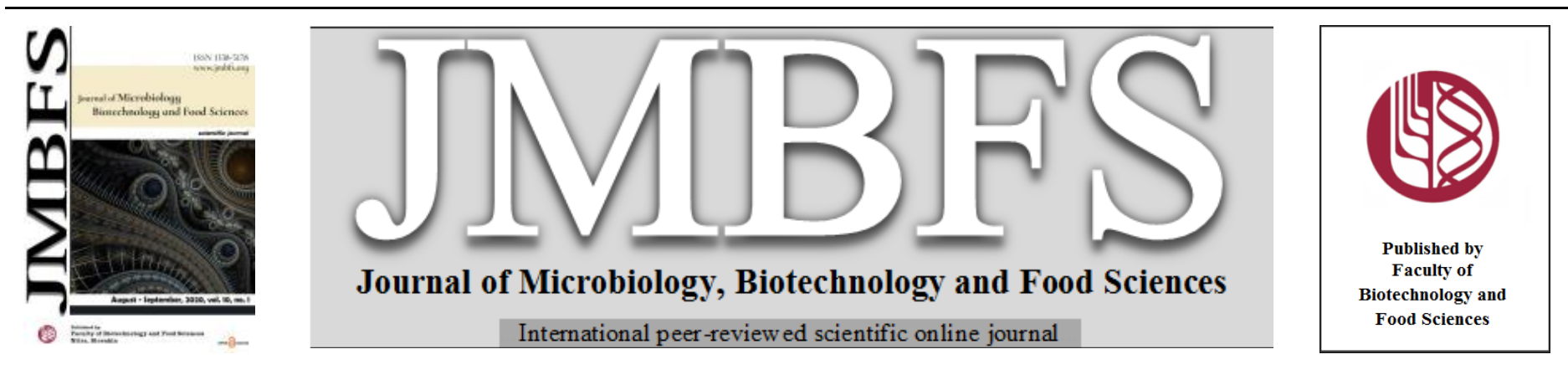

\title{
VALIDATED MICROBIOLOGICAL ASSAY FOR JOSAMYCIN DETERMINATION IN ITS PHARMACEUTICAL FORMULATIONS
}

\author{
Abdelghani Mahmoudi ${ }^{{ }^{1,2}}$, Said Zerkout ${ }^{2}$, Ann Van Schepdael ${ }^{1}$, Med Selah Boukhechem $^{2}$, Hadjera Boujella ${ }^{3}$, Laura-Mihaela Simon ${ }^{4}$, \\ Silvia De Francia ${ }^{5}$, Elisa Pirro ${ }^{5}$
}

Address(es): Dr. A. Mahmoudi, Pharmaceutical Analysis,

${ }^{1}$ Pharmaceutical Analysis, Department of Pharmaceutical and Pharmacological Sciences, Faculty of Pharmaceutical Sciences, KU Leuven - University of Leuven, Herestraat 49, O\&N2, PB 923, B-3000 Leuven, Belgium.

${ }^{2}$ Research Laboratory on Bioactive Products and Biomass Valorization (LPBVB), Ecole Normale Supérieure - Kouba, PB 92, 16038 Algiers, Algeria.

${ }^{3}$ Laboratory of Biology of Microbial Systems (LBMS), Ecole Normale Supérieure-Kouba, PB 92, 16038 Algiers, Algeria.

${ }^{4}$ Microbiology Department, Faculty of Medicine, "Iuliu Hatieganu" University of Medicine and Pharmacy, 4 Pasteur Street, 400349, Cluj-Napoca, Romania.

${ }^{5}$ Clinical Pharmacology, Department of Clinical and Biological Sciences, Faculty of Medicine, University of Turin, S. Luigi Gonzaga Hospital, Regione Gonzole 10,

10043 Orbassano (TO), Italy.

*Corresponding author: mahmoudi_a2003@yahoo.fr

doi: 10.15414/jmbfs.2020.10.1.33-37

\section{ARTICLE INFO}

Received 28. 8. 2019

Revised 27. 2. 2020

Accepted 4. 3. 2020

Published 1. 8. 2020

Short communication open $\odot$ access

\begin{abstract}
A simple, inexpensive and efficient agar diffusion bioassay, applying cylinder plate method, for determination of josamycin (JOS) in pure and pharmaceutical dosage forms was studied. Using a strain of Micrococcus luteus ATCC 9341 as the test organism, JOS at concentrations ranging from 0.1 to $0.5 \mu \mathrm{g} / \mathrm{mL}$ could be measured. The calibration graph was linear with good correlation coefficient $(\mathrm{r}=$ 0.999), and the method validation showed that it was specific and robust. The interference effects of degradation products and excipients were investigated in order to assess the method selectivity. The proposed method was successfully applied to estimate JOS content in tablets and suspension with good precision (intra-day $\mathrm{RSD}=0.87 \%$; inter-day $\mathrm{RSD}=1.25 \%$ ) and accuracy; the recovery values were between 97.74 and 101.13\%. Bioassay was correlated with UV spectrophotometric and high performance liquid chromatographic techniques. The results obtained by these three methods were statistically analyzed by analysis of variance (ANOVA), which indicated that there was no significant difference among these methods. Therefore, we recommend this microbiological assay for drug analysis in routine quality control of josamycin in pharmaceuticals as an alternative to the physicochemical methods reported in the literature.
\end{abstract}

Keywords: josamycin; microbiological assay; tablets; oral suspension; Micrococcus luteus ATCC 9341

\section{INTRODUCTION}

JOS, (3R,4R,5S,6R,8R,9R,10E,12E,15R)- 3-acetoxy- 5 -[O-2, 6-dideoxy- 4 -Oisovaleryl- 3 -C- methyl-a-L-ribo-hexopyranosyl-(1 $\rightarrow 4)$-3,6-dideoxy- 3 dimethylamino-b-D-glucopyranosyloxy]-6-formyl- methyl- 9 -hydroxy- 4 methoxy-8, 15-dimethyl-10, 12- pentadecadien-15-olide, is an effective antibiotic against mycoplasma, Gram-positive cocci, bacilli and certain Gram-negative organisms. Similar to 16-membered macrolides, JOS is a lipophilic molecule with a central lactone ring of 16 atoms, where several amino and sugar moieties are attached. Some of its pharmacokinetic properties are as follows: accumulation in certain cells and an increase in blood plasma levels after repeated ingestion (Omura, 2002; Bryskier et al., 1993; Kikuchi et al., 1998) (Figure 1).

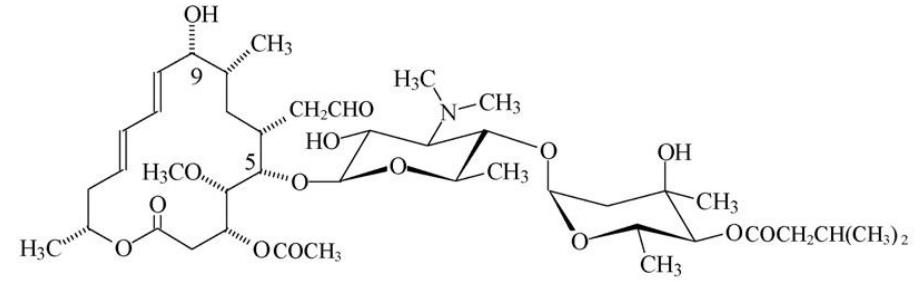

Figure 1 Chemical structure of josamycin

JOS is an antibiotic mainly employed in human medicine for the treatment of many infections of skin, respiratory tract, ear, nose and throat. Else, it is used in veterinary practice as feed additive or to treat some disease. JOS is a member of the leucomycin complex and has an action mechanism essentially based on protein synthesis inhibition: it binds to the ribosomal subunit (50S), hence blocking the entrance to the ribosomal tunnel. This leads to the arrest of the peptide growth, due to steric hindrance, and the dissociation of the peptidyltRNA (Omura et al., 1970).

JOS can be produced as commercial form by fermentation using Streptomyces narbonensis var. josamyceticus (Tenson et al., 2003). But, this method is not enough selective and several related compounds are produced. Consequently, a validated and selective method is required to quantify JOS in the presence of other compounds.

A literature review reveals numerous analytical methods for JOS analysis including microbiological assay (Bergan et al., 1972), thin layer chromatography (European Pharmacopoeia, 2010), spectrophotometry (Alarfaj et al., 2011) voltammetry (Belal et al., 2002), and capillary zone electrophoresis (Lalloo et al., 1997; Deng et al., 2007; Liu et al., 2010). High-performance liquid chromatography coupled to mass spectrometry (Govaerts et al., 2004; Dickson et al., 2014; Daidone et al., 2008; Van den Bossche et al., 2013), fluorescence detection (Tod et al., 1992), electrochemical detection (Gonzalez de la Huebra et al., 2007) and UV detection (Garcia-Mayor et al., 2015; Garcia-Mayor et al., 2006; Leal et al., 2001; Kanfer et al., 1998; Arsic et al., 2018) have been used to specifically investigate unchanged JOS. Nevertheless, the majority of these methods illustrate the investigation of JOS in biological fluids. Only some of them deal with the quantification of JOS as dosage form (Arsic et al., 2018). In general, most of the used techniques were time-consuming, and dedicated to sophisticated and expensive equipments (Mahmoudi et al., 2020).

In this present research, a validated and specific microbiological assay using the cylinder-plate technique was described for JOS quantification in pharmaceutical formulations as a substitute to the physicochemical procedures reported in the literature. The developed assay was validated in terms of: specificity, linearity, precision, accuracy and robustness. It was easily and effectively applied for the quantification of the pharmaceutical formulations. UV spectrophotometry and HPLC were used for a comparison study. 


\section{MATERIAL AND METHODS}

\section{Chemicals}

JOS standard was provided by Sigma-Aldrich (Steinheim, Germany). Tablets containing JOS were obtained commercially. Josacine ${ }^{\circledR}$ tablets (Astellas Pharma, France): labeled to contain JOS as $500 \mathrm{mg} /$ tablet. Josacine ${ }^{\circledR}$ oral suspension (Astellas Pharma, France): labeled to contain JOS as $125 \mathrm{mg} / 5 \mathrm{~mL}$. All drugs forms were employed without any purification phase. Working standards were prepared freshly every day.

Dipotassium hydrogen phosphate was of analytical-reagent grade from SigmaAldrich (Steinheim, Germany). Methanol was of HPLC grade from the same source. All other reagents were of analytical grade. Doubly distilled water was used throughout.

\section{Preparation of stock standard}

JOS stock standard solutions $(100 \mu \mathrm{g} / \mathrm{mL})$ were prepared by dissolving an equivalent quantity of macrolide in methanol $(10 \mathrm{mg} / 100 \mathrm{~mL}) .0 .025 \mathrm{M}$ dipotassium hydrogen phosphate buffer $(\mathrm{pH}$ 8.0) was used to prepare freshly solutions by an appropriate dilution. The solutions were prepared and used as working standards at concentrations of $0.1,0.3$ and $0.5 \mu \mathrm{g} / \mathrm{mL}$, which were used in the assay as reference solutions

\section{Preparation of pharmaceutical samples}

\section{Josacine $^{\circledR}$ tablets}

The sample preparation was performed based on an already published protocol (Mahmoudi et al., 2015; Mahmoudi et al., 2016, Mahmoudi, 2018). Ten tablets of Josacine ${ }^{\circledR}$ were weighed and then finely powdered after that. A weighed powder equivalent to $500 \mathrm{mg}$ was transferred into volumetric flasks of $100 \mathrm{~mL}$ containing some methanol $(20 \mathrm{~mL})$ and dissolved by ultrasonic bath for a period of $20 \mathrm{~min}$, after that the solution was completed to volume with the same solvent. The solution was mixed and filtered using a Millipore membrane filter. A precise volume of the filtrate was consequently diluted with the dipotassium hydrogen phosphate buffer $(\mathrm{pH} 8.0)$ solvent to obtain a sample solution that has a working concentration of $0.1,0.3$ and $0.5 \mu \mathrm{g} / \mathrm{mL}$. This sample was evaluated in triplicate. This process was done twice.

\section{Josacine $^{\circledast}$ oral suspension}

A weighed portion of the powder for oral suspension of JOS $(125 \mathrm{mg})$ was introduced into a volumetric flask of $100 \mathrm{~mL}$. Then $20 \mathrm{~mL}$ of methanol was added. The mixture was then sonicated (5 min), adjusted to mark and mixed well. The dilution method was followed to obtain a solution having the same working concentration range.

\section{Microbiological assay}

The bioassay applying the cylinder-plate diffusion technique reported in the US Pharmacopeia was employed (United States Pharmacopeia, 2007), and the parallel-line model was used. Differences were considered statistically significant if $\mathrm{P}$ was $<0.05$.

\section{Organism and inoculum}

In brief, the indicator organism was Micrococcus luteus ATCC 9341 applying the method of cylinder-plate. The cultures were cultivated in the freezer on Grove Randall number 1 agar (Merck) and pealed to another Grove Randall number 1 agar ( $24 \mathrm{~h}$ before the assay) that was kept in a stove at $35^{\circ} \mathrm{C}$. Grove Randall number 3 broth (Merck) was used to prepare the bacterium suspension $(25 \pm 2 \%$ transmittance at $580 \mathrm{~nm}$ ). The inoculated layer was prepared at $47 \pm 2{ }^{\circ} \mathrm{C}$ by adding $100 \mathrm{~mL}$ of Grove Randall number 11 agar (Merck) to $1 \mathrm{ml}$ of the inoculated Grove Randall number 3 broth.

\section{Method of cylinder-plate}

The microbiological assay followed the design of $3 \times 3$ parallel line, using eight plates for each test. The base agar layer consisted of $20 \mathrm{~mL}$ of medium No. 1 which was poured into a $100 \mathrm{~mm} \times 20 \mathrm{~mm}$ Petri dish. Subsequent the solidification of this layer, $5.0 \mathrm{~mL}$ portions of the inoculated medium 11 were poured onto that base agar layer. In each plate, nine stainless steel cylinders of a similar size $(8 \mathrm{~mm} \times 6 \mathrm{~mm} \times 10 \mathrm{~mm})$ were located on the surface of the inoculated medium. Each test was planned to estimate the reference solutions and two different samples in the same plate. Three cylinders were used for the reference solutions $(200 \mu \mathrm{L})$, while the others were employed for the sample solutions. After incubation $\left(24 \mathrm{~h}\right.$ at $35^{\circ} \mathrm{C}$ ) the zone diameters (in $\mathrm{mm}$ ) of the growth inhibition were carefully measured with caliper.

\section{Results calculation}

JOS potency in tablets solution was estimated using the Hewitt equation (Hewitt, 1977). The results were statistically treated by the model of linear parallel for the $3 \times 3$ design and by linear regression analysis. The bioassay was statistically validated using analysis of variance (ANOVA), to estimate the regression, parallelism and linearity of each assay. In order to ensure the statistical validity, the confidence interval $(\mathrm{P}=0.95)$ of each test was considered (United States Pharmacopeia, 2007; Hewitt, 1977; ICH-guidelines, 2011).

\section{Validation of analytical assay}

The proposed assay was further validated for selectivity, linearity, accuracy, precision and robustness according to frequently recommended references (United States Pharmacopeia, 2007; ICH-guidelines, 2011; Paim et al., 2011; Schmidt et al., 2009)

\section{Linearity}

Three doses of the reference solutions were used to plot the calibration curve Solutions of JOS at concentrations ranging from 0.1 to $0.5 \mu \mathrm{g} / \mathrm{mL}$ were prepared from stock standard. Linearity was investigated using linear regression by means of least squares.

\section{Assay precision}

Precision of the method was determined for repeatability and precision. Repeatability (intra-assay) was estimated by testing the same concentration of samples (tablets and suspension), using the same conditions and in the same day. Intermediate precision (inter-assay) was studied by doing the tests on three successive days (eight replicates per concentration). The results were expressed in \% relative standard deviation (\% RSD).

\section{Accuracy}

Accuracy of any analytical technique is defined as the closeness of the method results to the exact value. It was determined by adding known amounts of reference substance to the samples at three concentration values of the working solution $(n=3)$. For this purpose, quantities of 3,3 and $15 \mathrm{mg}$ of JOS were transferred to three volumetric flasks of 300,100 , and $300 \mathrm{~mL}$ respectively, and $1.0,1.0$ and $5.0 \mathrm{~mL}$ of reference solution $(300 \mu \mathrm{g} / \mathrm{mL}$ ) were added (in this same order). Then, buffer of dipotassium hydrogen phosphate was used to yield the final concentrations of $0.11,0.33$ and $0.55 \mu \mathrm{g} / \mathrm{mL}$. The solutions were assayed following the proposed bioassay and the percentage recovery of added reference was calculated by the equation of AOAC (Horwitz, 2000).

\section{Specificity}

Specificity includes a list of detailed requirements with which the products used or obtained during manufacturing have to be confirmed. The method capability to quantify JOS in the presence of the excipients and degradation substances was investigated. Thus, solutions were prepared, sonicated for 10 minutes, filtered and then assayed. The solvent, degradation products and placebo were individually tested in order to determine their individual activity and then they were compared with standard solution results and checked for any interference of extraneous substances present with JOS.

\section{Robustness study}

Method robustness is the evaluation of their ability to stay unchangeable by miniature variations in parameters of the procedure to indicate its reliability in case of the normal conditions. The robustness of this bioassay was investigated by assaying standard solutions at the same concentration $(0.5 \mu \mathrm{g} / \mathrm{mL})$ using a diversity of conditions. The changed parameters were inoculum concentration, incubation temperature and inoculated broth volume. Each factor was tested at two levels around their central point. The low $(-1)$, central $(0)$ and high $(+1)$ levels studied are listed in Table 1 . The obtained results of the different tests were analyzed by ANOVA and expressed in \% RSD.

Table 1 Investigated parameters in the robustness

\begin{tabular}{lccc}
\hline Conditions & Low level $(-1)$ & Central value $(0)$ & High level $(+1)$ \\
\hline $\begin{array}{l}\text { Inoculum } \\
\text { concentration }\end{array}$ & 1.8 & 2.0 & 2.2 \\
$\begin{array}{l}\text { I\%) } \\
\begin{array}{l}\text { Incubation } \\
\text { temperature }\end{array}\end{array}$ & 33 & 35 & \\
$\left({ }^{\circ} \mathrm{C}\right)$ & & & \\
$\begin{array}{l}\text { Inoculated layer } \\
(\mathrm{mL})\end{array}$ & 4.5 & 5.0 & 5.5 \\
\hline
\end{tabular}




\section{Comparison study}

The bioassay results were compared with a previously reported HPLC method (Leal et al., 2001) and a UV spectrophotometric method. UV spectrophotometric procedure was realized on a UV-Vis Spectrophotometer, model SPECORD ${ }^{\circledR}$ 250 Plus, Germany. JOS was detected at $232 \mathrm{~nm}$ using methanol as solvent.

\section{RESULTS AND DISCUSSION}

Choosing a suitable method of analysis is essential for quality control of pharmaceutical dosage forms and is based on numerous parameters like drug source, its complexity, sample quantity, availability of apparatus and reagents (Dafale et al., 2015). Recently and for many years, a considerable attention, principally from regulatory agencies, has focused on the development and validation of several techniques in order to determine the potency of drugs due to their significance in pharmaceutical analysis (Kanfer et al., 1998; Arsic et al., 2018). The potency of an antibiotic may be demonstrated under suitable conditions by comparing the inhibition of growth of sensitive microorganisms produced by known concentrations of the antibiotic to be examined and a reference standard (United States Pharmacopeia, 2007). From the tested strains, Micrococcus luteus ATCC 9341 was shown to be the best and the appropriate test microorganism in terms of its sensibility to JOS and ability to obtain sharply clear inhibition zones, which can help for easy measurements with high level of exactitude. In this study, the developed microbiological assay was described as a simple and an appropriate technique for JOS quantification in the pharmaceutical formulations.

\section{Method performance}

The studied microbiological assay was validated in terms of linearity, precision, accuracy, lower limit of detection, lower limit of quantification, robustness using ICH guidelines (ICH-guidelines, 2011; Breier et al., 2002).

Least square regression analysis was carried out for getting the slope, intercept, correlation coefficient and the relative standard deviation values. The results of mean zone diameters for reference solutions of JOS were: $15.81 \mathrm{~mm}$ $(\mathrm{RSD}=0.93 \%)$ for low dose $(0.1 \mu \mathrm{g} / \mathrm{mL}), 20.02 \mathrm{~mm}(\mathrm{RSD}=0.62 \%)$ for medium dose $(0.3 \mu \mathrm{g} / \mathrm{mL})$ and $21.74 \mathrm{~mm}(\mathrm{RSD}=0.88 \%)$ for high dose $(0.5 \mu \mathrm{g} / \mathrm{mL})$.

\section{Selectivity}

Method specificity is the capability of the microbiological assay to distinguish the studied analyte from the other interfering products. It serves as a backbone for quality evaluation. To estimate the specificity of the described bioassay, JOS standard was spiked with excipients and evaluated. No interference was observed during the examination of JOS, which indicates that this procedure is specific for JOS analysis in the pharmaceutical forms, indicating the good selectivity of the developed bioassay towards the interfering compounds.

\section{Linearity and sensitivity}

Linearity of any method is defined as its capability (within a given range) to give results values directly proportional to analyte quantity (concentration) in their sample. Linearity is generally reported as slope variance of the regression line. To verify the proposed bioassay linearity, a calibration curve was established using three concentrations. The linearity of the responses for JOS was determined in the concentration range of $0.1-0.5 \mu \mathrm{g} / \mathrm{mL}$ by plotting the diameters of the inhibition zones $(\mathrm{mm})$ against the logarithm of the drug concentrations $(\mu \mathrm{g} / \mathrm{mL})$ (Fig. 2). The analytical data for the calibration graphs were listed in Table 2 Linear response of calibration graph was observed over the range of used concentrations with a correlation coefficient (r) greater than 0.989. Limit of quantification (LOQ) is the lowest value of analyte concentration which can be estimated with satisfactory precision under the stated experimental conditions.
LOD and LOQ were found to be 0.03 and $0.10 \mu \mathrm{g} / \mathrm{mL}$, respectively, indicating an adequate sensitivity of the bioassay. Thus, LOD and LOQ values demonstrate that considered microbiological assay is sufficiently sensitive for JOS quantification in pure form and pharmaceutics (such as tablets and oral suspension)

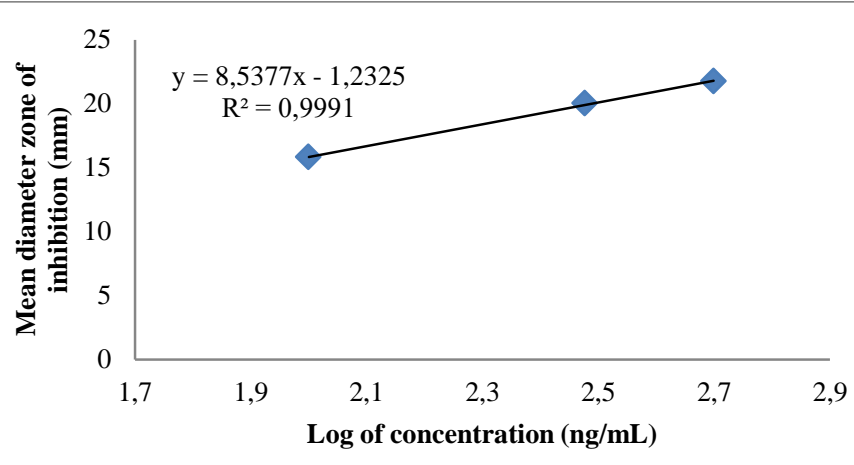

Figure 2 JOS calibration curve

Table 2 Statistical factors of JOS analysis using the studied bioassay.

\begin{tabular}{lc}
\hline Linear range $(\mu \mathrm{g} / \mathrm{mL})$ & $0.1-0.5$ \\
\hline Regression equation $(y=a+b \mathrm{c})^{\mathrm{a}}$ & \\
Slope $(\mathrm{a})$ & 8.537 \\
Intercept $(\mathrm{b})$ & -1.232 \\
Correlation coefficient $(\mathrm{r})$ & 0.999 \\
Detection limit $(\mu \mathrm{g} / \mathrm{mL})$ & 0.03 \\
Quantification limit $(\mu \mathrm{g} / \mathrm{mL})$ & 0.10 \\
\hline a $\mathrm{y}:$ diameter of the inhibition zone in $\mathrm{mm}, \mathrm{c}:$ logarithm of the drug concentration \\
in $\mathrm{ng} / \mathrm{mL}$
\end{tabular}

\section{Precision evaluation}

Precision of any method defined as the closeness of agreement between a series of obtained determinations from multiple sampling of the same sample using a normal operation. In accordance with ICH (ICH-guidelines, 2011), precision should be evaluated at different levels such as repeatability (Intra-day precision) and intermediate precision (Inter-day precision).

Repeatability of individual measurements is expressed as \% relative standard deviation. It was determined by preparing the sample solution at the concentration of $0.5 \mu \mathrm{g} / \mathrm{mL}$ and six replicates $(n=6)$ on the same day, and then the $\%$ RSD of the obtained values was estimated.

The intermediate precision was evaluated by testing samples at three level of concentrations $(0.1,0.3$ and $0.5 \mu \mathrm{g} / \mathrm{mL})$ over three successive days $(\mathrm{n}=3)$. Interday precision was studied by analyzing JOS in tablets and suspension with eight replicates per concentration.

The obtained values of $\%$ RSD varied in the range of $0.58-0.87 \%$ for intra-day precision and $1.02-1.25 \%$ for inter-day precision (Table 3 ). The individual and the low values of \%RSD observed are within acceptance criteria, which indicates that the method is precise.

\section{Accuracy estimation}

Accuracy of any technique of analysis is defined as the closeness of agreement between the accepted value either as a conventional true value or an accepted reference value and the value found. Accuracy represents the total of systematic (trueness) and random errors and consequently, expresses the inherent total error of the result.

\begin{tabular}{|c|c|c|c|c|c|c|c|c|c|}
\hline \multirow[t]{2}{*}{ Sample } & \multirow{2}{*}{$\begin{array}{l}\text { Claimed } \\
\text { conc }^{\text {a }} \text {. }\end{array}$} & \multicolumn{6}{|c|}{ Experimental amount ${ }^{\mathrm{b}}(\mathrm{mg})$} & \multirow[t]{2}{*}{$\%$ Level } & \multirow[t]{2}{*}{$\% \mathrm{RSD}$} \\
\hline & & 1 & 2 & 3 & 4 & 5 & 6 & & \\
\hline \multicolumn{10}{|l|}{ Intra-assay } \\
\hline Josacin $®$ tablet & 500 & 490.85 & 503.07 & 498.79 & 502.34 & 498.89 & 497.98 & 99.73 & 0.87 \\
\hline $\begin{array}{l}\text { Josacin }{ }^{\circledR} \\
\text { suspension }\end{array}$ & 125 & 122.94 & 124.08 & 124.65 & 123.48 & 124.55 & 123.16 & 99.05 & 0.58 \\
\hline Inter-assay & & & & & & & & & \\
\hline Josacin $®$ tablet & 500 & 492.58 & 485.09 & 497.31 & 498.42 & 488.74 & 493.17 & 98.51 & 1.02 \\
\hline $\begin{array}{l}\text { Josacin }{ }^{\circledR} \\
\text { suspension }\end{array}$ & 125 & 124.73 & 121.13 & 123.09 & 121.35 & 122.21 & 124.44 & 98.26 & 1.25 \\
\hline
\end{tabular}

${ }^{\mathrm{a}} \mathrm{mg} /$ tablet for Josacin $\left(\AA\right.$ tablet and $\mathrm{mg} / 5 \mathrm{~mL}$ for Josacin ${ }^{\circledR}$ suspension

${ }^{\mathrm{b}}$ Each value is the mean of eight analyses. 
Bioassay accuracy was evaluated by recovery studies of the drug. To the formulations (analysed samples), the reference standard was added at three levels, and subsequently assayed. Study of recovery was established three times. Recovery percentage and mean recovery percentage were determined and represented in Table 4.

Accuracy of the studied drug was evaluated as mean $\%$ recoveries $(n=8)$ and the found values were within $97.74-101.13 \%$, which is satisfactory and indicates the good accuracy of the bioassay.

\section{Robustness study}

Robustness of a technique is its aptitude to stay unaffected by any deliberate changes in their parameters. Changing the experimental factors was realized to supply a guarantee about its reliability using normal conditions. Hence, to test the bioassay robustness, a number of conditions were changed from their central point. The following conditions were assayed: inoculum concentration $(2 \pm 0.2 \%)$, incubation temperature $\left(35 \pm 2{ }^{\circ} \mathrm{C}\right)$ and volume (thickness) of inoculated laye $(5 \pm 0.5 \mathrm{~mL})$, and the obtained data were shown in Table 5. According the experimental values and by applying ANOVA, no significant influence was noted on these results. The results varied within 98.9-100.9\%, with \% RSD values less than $1 \%$, there by demonstrating that the proposed bioassay is robust enough.

Table 4 Recovery results of JOS analysis in samples, by the proposed bioassay.

\begin{tabular}{|c|c|c|c|}
\hline \multirow[t]{2}{*}{ Sample } & \multicolumn{2}{|c|}{ Amount of reference $(\mu \mathrm{g})$} & \multirow[t]{2}{*}{$\%$ Recovery $^{\mathrm{a}}$} \\
\hline & Added & Recovered & \\
\hline \multirow[t]{3}{*}{ Josacin $\AA$ tablet } & 0.01 & 0.00981 & 98.10 \\
\hline & 0.03 & 0.03034 & 101.13 \\
\hline & 0.05 & 0.04911 & 98.22 \\
\hline \multirow{3}{*}{$\begin{array}{l}\text { Josacin }{ }^{\circledR} \\
\text { suspension }\end{array}$} & 0.01 & 0.00979 & 97.90 \\
\hline & 0.03 & 0.02952 & 98.40 \\
\hline & 0.05 & 0.04887 & 97.74 \\
\hline
\end{tabular}

${ }^{\mathrm{a}}$ For each value, $\mathrm{n}=8$.

Table 5 Experimental values of robustness assayed at $100 \%$ theoretical concentration of JOS

\begin{tabular}{lccc}
\hline Conditions & Investigated range & $\begin{array}{c}\text { Potency found } \\
(\%)\end{array}$ & RSD (\%) \\
\hline Inoculum & 1.8 & 98.9 & \\
concentration $(\%)$ & 2.0 & 100.4 & 0.84 \\
& 2.2 & 99.0 & \\
Incubation & 33 & 100.9 & \multirow{2}{*}{0.86} \\
temperature $\left({ }^{\circ} \mathrm{C}\right)$ & 35 & 100.3 & \\
& 37 & 99.2 & 0.35 \\
Inoculated layer & 4.5 & 99.1 & \\
$(\mathrm{~mL})$ & 5.0 & 100.2 & \\
& 5.5 & 99.5 & \\
\hline
\end{tabular}

\section{Comparison of different methods}

In this part, a comparative study was realized between the considered microbiological assay and a reported HPLC and UV spectrophotometry method. JOS tablets were assayed by the developed method, and then the potency percentage was estimated as $99.67 \%$. The percentage contents were found to be $100.34 \%$ and $101.01 \%$ by the HPLC and UV spectrophotometry methods, respectively, which are equivalent (Table 6). Using both methods, results were established within the acceptable limits of $95-105 \%$ and indicate a good correlation between the studied techniques. However, determining the bioactivity by means of microbiological method is an effectual procedure of estimating the subtle change in macrolides and the other antibiotics. Furthermore, microbiological assay is not more costly and is suitable for drug dynamics studies.

JOS content in the pharmaceutical forms was determined by the HPLC and microbiological assay, and the results indicate a good correlation (Fig. 3). The linear curve equation was $y=1.014 x+0.018\left(n=12 ; r^{2}=0.986\right)$. HPLC technique using UV detection has a high specificity and repeatability. Nevertheless, crossreferencing the procedure with a studied microbiological assay makes a possibility to provide more precise data.

Table 6 Analysis of JOS in tablets by the different used methods.

\begin{tabular}{lccc}
\hline Sample & UV & HPLC & Microbiological \\
\hline 1 & 101.88 & 98.96 & 98.74 \\
2 & 101.97 & 100.79 & 98.25 \\
3 & 98.99 & 99.74 & 100.55 \\
4 & 102.57 & 101.31 & 100.93 \\
5 & 99.64 & 100.89 & 99.90 \\
Average of & 101.01 & 100.34 & 99.67 \\
determinations & & & \\
\hline
\end{tabular}

Physicochemical techniques like HPLC and UV spectrophotometry, can be used for quantitative determination of antibiotics with high precision, but they cannot offer any accurate data about biological activity. Many attempts were carried out to correlate the antibiotic analysis results obtained from these methods with those from microbiological assay, but they have disappointed (Cazedey et al., 2013). However, the microbiological tests have certain changeability, but the finding of the present study confirmed that the developed microbiological assay will be more practical for quantification of the considered macrolide in its pharmaceutics, being an adequate substitute technique for routine control of quality of JOS.

Bioassay finding shows that UV spectrophotometry and bioassay methods are relatively inexpensive and simple compared to HPLC assay methods. They are effective in the determination of the quality and quantity of the active substance in JOS tablets. Based on the results obtained from these methods, it is very important to combine various simple, precise and sensitive methods of analysis to authenticate the quality of drug samples because of error and limitation of some of the analytical methods. When a drug conforms to standards as stated in the official monograph, it gives assurance of the quality and predicts therapeutic efficacy as well as drug security. Hence, it is better to use more than one analytical method in the determination of the quality of active drug in pharmaceutical preparations.

\section{CONCLUSION}

A new precise and reliable microbiological assay for estimation of JOS in tablets and oral suspensions was described. The described technique was validated for selectivity, linearity, accuracy, precision and robustness at a range of concentrations varied from 0.1 to $0.5 \mu \mathrm{g} / \mathrm{mL}$, and establishes to be precious to analyze and detect JOS antibiotic in their pharmaceutical formulations. The proposed method gave satisfactory results and proved that it is a good alternative methodology as a complement or replacement for the actual physicochemical techniques. The results indicate the possibility to quantify the investigated drug in the presence of excipients. This assay uses no toxic reagents, with uncomplicated preparation phase of sample, encouraging its use in routine applications. The developed bioassay can be also applied for biomedical purposes.

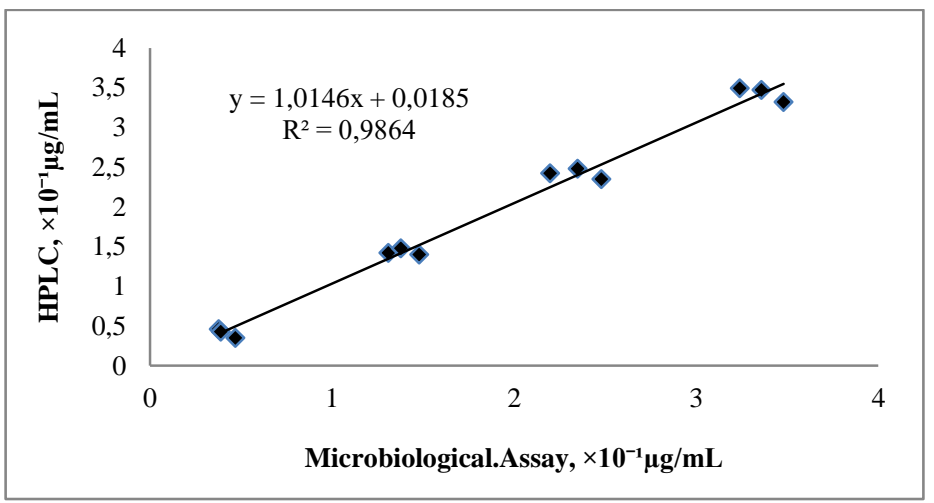

Figure 3 Correlation between HPLC and microbiological assay corresponding to JOS analyzed in tablets: $y=1.014 x+0.018 ; r^{2}=0.986 ; n=12$.

Acknowledgements: The authors would like to thank Natural Sciences Department and Microbiology Laboratories of Ecole Normale SupérieureKouba, Algiers, Algeria, for their support and providing the necessary facilities to perform this scientific research.

\section{REFERENCES}

ALARFAJ, N.A., RAZEQ, S.A.A., ALSEHALY, H.M. 2011. Determination of Josamycin and Ciprofloxacin in their Pharmaceutical Dosage Forms by Spectrophotometry. Asian. J. Chem, 23, 3362-3366.

ARSIC, B., BARBER, J., ČIKOŠ, A., MLADENOVIC, M., STANKOVIC, N., NOVAK, P. 2018. 16-membered macrolide antibiotics: a review. Int. J. $\begin{array}{lll}\text { Antimicrob. } & \text { Agents, } & \text { 283-298. }\end{array}$ https://doi.org/10.1016/j.ijantimicag.2017.05.020

BELAL, F., AL-MAJED, A., IBRAHIM, K.E.E., KHALIL, N.Y. 2002 Voltammetric determination of josamycin (a macrolide antibiotic) in dosage forms and spiked human urine. J. Pharm. Biomed. Anal, 30, 705- 713. https://doi.org/10.1016/S0731-7085(02)00358-8

BERGAN, T., OYDVIN, B. 1972. Microbiological assay of josamycin. Acta. Pathol. Microbiol. Scand. B. Microbiol. Immunol, 80, 101-6. https://doi.org/10.1111/j.1699-0463.1972.tb00134.x

BREIER, A.R., GARCIA, C.V., OPPE, T.P., STEPPE, M., SCHAPOVAL, E.E. 2002. Microbiological assay for azithromycin in pharmaceutical formulations. $J$. Pharm. Biomed. Anal, 29, 957-961. https://doi.org/10.1016/S07317085(02)00213-3 
BRYSKIER, A., AGOURIDAS, C., GASC, J.C., in: BRYSKIER, A., BUZLER, J.P., NEU, H.C., TULKENS P.M. (Eds.), 1993, Macrolides, Chemistry, Pharmacology and Clinical Uses, Arnette-Blackwell, Oxford, pp. 24-29.

CAZEDEY, E.C.L., SALGADO H.R.N. 2013. A novel and rapid microbiological assay for ciprofloxacin hydrochloride. J. Pharm. Anal, 3, 382-386 https://doi.org/10.1016/j.jpha.2013.03.007

DAFALE, N.A., SEMWAL, U.P., AGARWAL, P.K., SHARMA, P., SINGH, G.N. 2015. Development and validation of microbial bioassay for quantification of Levofloxacin in pharmaceutical preparations. J. Pharm. Anal, 5, 18-26. https://doi.org/10.1016/j.jpha.2014.07.007

DAIDONE, F., HEUVELMANS, R., AERDEN, L., HOOGMARTENS, J., ADAMS, E. 2008. Development of a liquid chromatographic method for the analysis of josamycin. J. Pharm. Biomed. Anal, 48, 347-55 https://doi.org/10.1016/j.jpba.2008.02.002

DENG, B., KANG, Y., LI, X., XU, Q. 2007. Determination of josamycin in rat plasma by capillary electrophoresis coupled with post-column electrochemiluminescence detection. J. Chromatogr. B, 859, 125-130 https://doi.org/10.1016/j.jchromb.2007.09.014

DICKSON, L.C. 2014. Performance characterization of a quantitative liquid chromatography-tandem mass spectrometric method for 12 macrolide and lincosamide antibiotics in salmon, shrimp and tilapia. J. Chromatogr. B, 967 203-210. https://doi.org/10.1016/j.jchromb.2014.07.031

EUROPEAN PHARMACOPOEIA. 2010. Directorate for the quality of medicines of the Council of Europe (EDQM), Supplement 6.8, Strasbourg, France, pp. 5963-9635.

GARCIA-MAYOR, M.A., GARCINUNO, R.M., FERNANDEZ-HERNANDO, P., DURAND-ALEGRIA, J.S. 2006. Liquid chromatography-UV diode-array detection method for multi-residue determination of macrolide antibiotics in sheep's milk. J. Chromatogr. A, 1122, 76-83. https://doi.org/10.1016/j.chroma.2006.04.019

GARCIA-MAYOR, M.A., PANIAGUA-GONZALES, G., SOLEDADRODRIGUEZ, B., GARCINUNO-MARTINEZ, R.M., FERNANDEZHERNANDO, P., DURAND-ALEGRIA, J.S. 2015. Occurrence of erythromycin residues in sheep's milk. Validation of an analytical method. Food. Chem Toxicol, 78, 26-32. https://doi.org/10.1016/j.fct.2014.12.020

GONZALEZ DE LA HUEBRA, M.J., VINCENT, U., VON HOLST, C. 2007 Sample preparation strategy for the simultaneous determination of macrolide antibiotics in animal feedingstuffs by liquid chromatography with electrochemical detection (HPLC-ECD). J. Pharm. Biomed. Anal, 43, 16281637. https://doi.org/10.1016/j.jpba.2006.12.008

GOVAERTS, C., CHEPKWONY, H.K., VAN SCHEPDAEL, A., ADAMS, E., ROETS, E., HOOGMARTENS, J. 2004. Application of liquid chromatographyion trap mass spectrometry to the characterization of the 16-membered ring macrolide josamycin propionate. J. Mass Spectrom, 39, 437-446. https://doi.org/10.1002/jms.612

HEWITT, H. 1977. Microbiological Assay: An Introduction to Quantitative Principles and Evaluation, Academic Press, New York

HORWITZ, W. 2000. Official Methods of Analysis of AOAC International, 17th ed., Section 988.08, AOAC International, Arlington.

ICH-GUIDELINES. 2011. Validation of Analytical Procedures, Methodology International Council on Harmonization of Technical Requirements for Registration of Pharmaceuticals for Human Use, Geneva, Switzerland.

KANFER, I., SKINNER, M.F., WALKER, R.B. 1998. Analysis of macrolide antibiotics. J. Chromatogr. A, 812, 255-286. https://doi.org/10.1016/S00219673(98)00276-3

KIKUCHI, Y., TERAMURA, T., SEKINO, J., NISHIMURA, T., MIURA, H., WATANABE, T., HIGUCHI, S. 1998. Sensitive and specific method for the determination of josamycin in human plasma by liquid chromatography-mass spectrometry. J. Chromatogr. B, 720, 81-87. https://doi.org/10.1016/S0378 4347(98)00430-7

LALlOO, A.K., CHATTARAJ, S.C., KANFER, I. 1997. Development of a capillary electrophoretic method for the separation of the macrolide antibiotics, erythromycin, josamycin and oleandomycin. J. Chromatogr. B, 704, 333-341. https://doi.org/10.1016/S0378-4347(97)00456-8

LEAL, C., CODONY, R., COMPANO, R., GRANADOS, M., PRAT, M.D. 2001. Determination of macrolide antibiotics by liquid chromatography. $J$. Chromatogr. A, 910, 285-290. https://doi.org/10.1016/S0021-9673(00)01231-0

LIU, Y-M., SHI, Y-M., LIU, Z-L., TIAN, W. 2010. A sensitive method for simultaneous determination of four macrolides by $\mathrm{CE}$ with electrochemiluminescence detection and its applications in human urine and tablets. Electrophoresis, 31, 364-370. https://doi.org/10.1002/elps.200900302 MAHMOUDI, A. 2018. Efficient and simple HPLC method for spiramycin determination in urine samples and in pharmaceutical tablets. Sep. Sci. plus, 1-8 https://doi.org/10.1002/sscp.201800014

MAHMOUDI, A., BOUKHECHEM, M. 2020. Simplified HPLC method for simultaneous determination of erythromycin and tretinoin in topical gel form. Sep. Sci. plus, 1-8. https://doi.org/10.1002/sscp.201900093

MAHMOUDI, A., DE FRANCIA, S., BOUKHECHEM, M., PIRRO, E. 2016 Quantification of three macrolide antibiotics in pharmaceutical lots by HPLC:
Development, validation and application to a simultaneous separation. $\mathrm{Br} . J$ Pharm, 1, 63-73. https://doi.org/10.5920/bjpharm.2016.03

MAHMOUDI, A., FOURAR, R., BOUKHECHEM, M., ZARKOUT, S. 2015 Microbiological assay for the analysis of certain macrolides in pharmaceutical dosage forms. Int. J. Pharm, 491, 285-291. https://doi.org/10.1016/j.ijpharm.2015.06.027

OMURA, S. 2002. Macrolide Antibiotics, Chemistry, Biology, and Practice, second ed. Academic Press, London.

OMURA, S., HIRONAKA, Y., HATA, T. 1970. Chemistry of leucomycin. IX Identification of leucomycin A3 with josamycin. J. Antibiot, 23, 511-513.

PAIM, C.S., FÜHR, F., BARTH, A.B., GONÇALVES, C.E., NARDI, N., STEPPE, M., SCHAPOVAL, E.E. 2011. Gemifloxacin mesylate (GFM) stability evaluation applying a validated bioassay method and in vitro cytotoxic study. Talanta, 83, 1774-1779. https://doi.org/10.1016/j.talanta.2010.11.069

TENSON, T., LOVMAR, M., EHRENBERG, M. 2003. The mechanism of action of macrolides, lincosamides and streptogramin $\mathrm{B}$ reveals the nascent peptide exit path in the ribosome. J. Mol. Biol, 330, 1005-1014 https://doi.org/10.1016/S0022-2836(03)00662-4

SCHMIDT, C. A., AGARRAYUA, D.A., LAPORTA, L.V., MACHADO, J.C., MANFIO, M.L., C.F. BITTENCOURT. 2009. Development and validation of a microbiological agar assay for determination of cefuroxime sodium in pharmaceutical preparations. J. Microbiol. Methods, 77, 308-315. https://doi.org/10.1016/j.mimet.2009.03.012

TOD, M., BIAREZ, O., NICOLAS, P., PETITJEAN, O. 1992. Sensitive determination of josamycin and rokitamycin in plasma by high-performance liquid chromatography with fluorescence detection. J. Chromatogr. B, 575, 171176. https://doi.org/10.1016/0378-4347(92)80521-Q

UNITED STATES PHARMACOPEIA. 2007. National Formulary, 26th ed., Rockville, MD,USA.

VAN DEN BOSSCHE, L., DAIDONE, F., VAN SCHEPDAEL, A HOOGMARTENS, J., ADAMS, E. 2013. Characterization of impurities in josamycin using dual liquid chromatography combined with mass spectrometry. J. Pharm. Biomed. Anal, 73, 66- 76. https://doi.org/10.1016/j.jpba.2012.01.012 